Article

\title{
Impact of the COVID-19 Outbreak on Air Quality in Korea
}

\author{
Ji Hoon Seo ${ }^{1,2}$, Hyun Woo Jeon ${ }^{3}$, Ui Jae Sung ${ }^{1}$ and Jong-Ryeul Sohn ${ }^{1,2,3, * \mathbb{D}}$ \\ 1 Department of Health \& Environmental Science, Korea University, Seoul 02841, Korea; \\ wlgns304@korea.ac.kr (J.H.S.); suj0510@korea.ac.kr (U.J.S.) \\ 2 BK21PLUS Program in Embodiment: Health-Society Interaction, Department of Public Health Sciences, \\ Graduate School, Korea University, Seoul 02841, Korea \\ 3 Department of Health and Safety Convergence Science, Korea University, Seoul 02841, Korea; \\ 2012250541@korea.ac.kr \\ * Correspondence: sohn1956@korea.ac.kr
}

Received: 23 September 2020; Accepted: 19 October 2020; Published: 21 October 2020

\begin{abstract}
The COVID-19 pandemic has led countries to take action, which has included practicing social distancing or lockdown. Many cities are experiencing air quality improvements due to human activity restrictions. The purpose of this study was to compare the air quality between 2020 and the previous three years, focusing on the two cities (Seoul and Daegu) where coronavirus is spreading the fastest in Korea. Significant decreases in $\mathrm{PM}_{2.5}, \mathrm{PM}_{10}, \mathrm{CO}$, and $\mathrm{NO}_{2}$ were observed in both cities. In particular, compared to the same period of 2017-2019, in March 2020, $\mathrm{PM}_{2.5}$ showed remarkable reductions of $36 \%$ and $30 \%$ in Seoul and Daegu, respectively. The effects of social distancing have maximized improvements in air quality due to reduced transboundary pollutants. The $\mathrm{PM}_{2.5} / \mathrm{PM}_{10}$ ratio was significantly reduced after social distancing, indicating that the contribution of traffic-related $\mathrm{PM}_{2.5}$ declined. Air quality improved overall from January to July, and the most noticeable drop in the air quality index (AQI) was observed in April. These findings indicate that relatively weak social distancing measures compared to a COVID-19 lockdown can help reduce air pollutant levels. At the same time, however, changes in air quality in the neighboring countries caused by COVID-19 control action are affecting Korea.
\end{abstract}

Keywords: COVID-19; air quality; social distancing; particulate matter; $\mathrm{PM}_{2.5}$

\section{Introduction}

The novel coronavirus (COVID-19), which was first reported in Wuhan on December 31, 2019, is spreading rapidly around the world and was declared a pandemic by the World Health Organization (WHO) in March 2020 [1]. In Korea, the first confirmed COVID-19 case was reported on January 20, 2020, and the number of confirmed COVID-19 cases began to explode around Seoul and Daegu, reaching 19,947 cases by 31 August 2020.

In countries where COVID-19 is spreading, national decisions are being made that range from social distancing to nationwide lockdowns to stop the spread of the infection [2]. As a result, human activities have become limited, causing traffic, industrial, and domestic emissions, which contribute to air pollution [3-5], to decrease. In many studies, changes in air quality across the world due to COVID-19 lockdown have been observed. In particular, significant reductions in atmospheric fine particulates $\left(\mathrm{PM}_{2.5}\right)$, respirable suspended particulates $\left(\mathrm{PM}_{10}\right)$, nitrogen dioxide $\left(\mathrm{NO}_{2}\right)$, carbon monoxide $(\mathrm{CO})$, and sulfur dioxide $\left(\mathrm{SO}_{2}\right)$ concentrations in 2020 (compared to the last three years) were observed in central China [6] where novel coronavirus first broke out. Likewise, positive effects on air quality have also been reported in the United States [7,8], Italy [9,10], India [3,11,12], and Brazil $[2,13,14]$, which are also experiencing COVID-19 infections. 
Air quality deterioration has a serious effect on human health and contributes to 5 million deaths worldwide every year. It is the fifth highest health-related factor causing disease in humans. Especially in Southeast Asia, up to $15 \%$ of the deaths were due to air pollution [15]. Air pollution in Korea has been highlighted as an environmental issue, causing 14,700 deaths in 2000 and 17,300 deaths in 2017 [16].

COVID-19 is causing a great deal of disease burden and worldwide economic deterioration [17], but it has enabled us to assess the air quality changes [18] induced by reduced industry and human activities. In previous studies, although social distancing is a weaker measure than COVID-19 lockdown, a significant improvement in air quality has been observed [19], immediately after the announcement of social distancing guidelines. In addition, In Sao Paulo, Brazil, which adopted social distancing similar to Korea, $\mathrm{PM}_{2.5}, \mathrm{PM}_{10}$, and $\mathrm{NO}_{2}$ decreased by $46 \%, 45 \%$, and $58 \%$, respectively, due to limited human activity [3].

Previous studies have observed changes in the national average air pollution level [20] but have not analyzed the impact of social distancing centered on metropolitan cities, which have an overwhelming number of COVID-19 cases. In addition, partial decrease in concentrations of air pollutants was observed, but there is no long-term analysis of the air quality index (AQI) that can represent air quality.

Korea experienced SARS-CoV (severe acute respiratory syndrome) in 2003 and the Middle East respiratory syndrome (MERS-CoV) in 2015, with MERS-CoV in particular, recording the second-highest number of confirmed cases in the world after Saudi Arabia. However, no studies have been conducted to assess air quality in the wake of past human coronavirus $(\mathrm{HCoV})$ outbreaks.

In this study, six typical air pollutants were observed in a time series, and the AQI was analyzed to observe changes in air quality caused by coronavirus diffusion and social distancing. In particular, we focused on the two representative cities (Seoul and Daegu) with the largest number of COVID-19 infections, and evaluated (1) the annual difference in air pollution before and after COVID-19 and MERS-CoV (compared to the past three years), (2) the trend in the $\mathrm{PM}_{2.5} / \mathrm{PM}_{10}$ ratio changes according to the level of social distancing, and (3) AQI changes and its major contributing pollutants after COVID-19 control actions.

\section{Methods}

\subsection{Site Description}

Seoul $\left(37^{\circ} 33^{\prime} \mathrm{N}, 126^{\circ} 58^{\prime} \mathrm{E}\right)$ and Daegu $\left(35^{\circ} 48^{\prime} \mathrm{N}, 128^{\circ} 33^{\prime} \mathrm{E}\right)$, the two cities with the highest number of COVID-19 cases in Korea, were selected as study areas (Figure 1). Seoul, which has the top population density among the capitals of the Organization for Economic Co-operation and Development (OECD) countries [21], has experienced a steady outbreak of mass infections regardless of social distancing practices. Daegu, the third largest and fourth most populous city, saw a surge in the number of confirmed cases in the early stages of the COVID-19 outbreak, which led to strict social distancing guidelines, but it still had the highest number of confirmed cases (35.3\%) in South Korea by August 2020.

\subsection{COVID-19 Data}

The daily identification of confirmed COVID-19 cases in Korea was provided by the Ministry of Health and Welfare of South Korea (MOHW) [22] and subdivided into Seoul and Daegu areas. Changes in the level of social distancing guidelines were announced by the MOHW. The recommendations of the South Korean government's social distancing step-by-step guidelines to prevent the spread of COVID-19 are presented in Table 1. South Korea has shifted from a social distancing campaign to a more relaxed way, known as "distancing in daily life", after new coronavirus cases dropped to single digits (March 6). These new quarantine protocols helped the public stay safe at home, work, and during outdoor activities now that gatherings and events are allowed. 


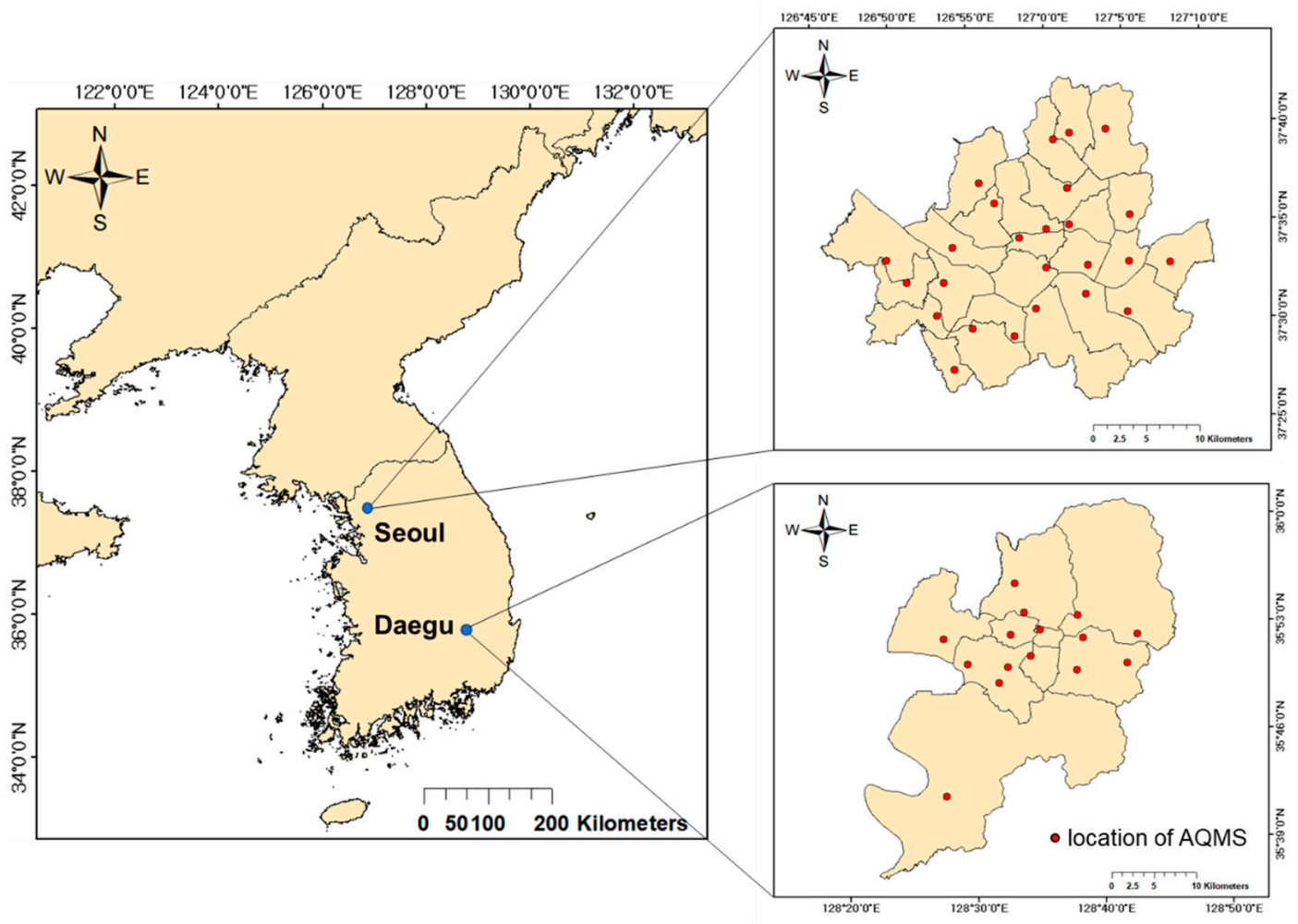

Figure 1. Location of Seoul and Daegu in Korea. Red dots present the location of air quality monitoring stations (AQMS). This map was produced by using ArcMap 10.6 of ArcGIS software.

Table 1. Guidelines on social distancing issued by the Government of South Korea.

\begin{tabular}{|c|c|c|c|}
\hline \multirow{2}{*}{ Category } & \multicolumn{3}{|c|}{ Level of Social Distancing } \\
\hline & Level 1 & Level 2 & Level 3 \\
\hline Personal hygiene & \multicolumn{3}{|c|}{$\begin{array}{l}\text { Wash your hands carefully for more than } 30 \mathrm{~s} \text { with soap, } \\
\text { Maintain at least } 1 \sim 2 \mathrm{~m} \text { distance with others }\end{array}$} \\
\hline Gatherings, events, etc. & $\begin{array}{l}\text { Allowed, recommended to } \\
\text { respect the sanitary measures }\end{array}$ & $\begin{array}{l}\text { All private and public } \\
\text { indoor meetings of } 50 \text { or } \\
\text { more and outdoor meetings } \\
\text { of over } 100 \text { are banned }\end{array}$ & $\begin{array}{l}\text { All private and public indoor } \\
\text { and outdoor meetings of } \\
\text { over } 10 \text { are banned }\end{array}$ \\
\hline Sport events & $\begin{array}{l}\text { Limited the number } \\
\text { of spectators }\end{array}$ & No spectators & Banned \\
\hline Public facilities & $\begin{array}{l}\text { Allowed (if necessary, they } \\
\text { can be suspended) }\end{array}$ & Suspended & Suspended \\
\hline Private facilities & $\begin{array}{c}\text { Allowed (high-risk places can } \\
\text { be suspended) }\end{array}$ & $\begin{array}{l}\text { All high-risk places are } \\
\text { closed, and sanitary } \\
\text { measures are reinforced. }\end{array}$ & $\begin{array}{l}\text { All high-risk places are } \\
\text { closed, and sanitary } \\
\text { measures are reinforced. }\end{array}$ \\
\hline Schools, kindergartens & Open and distance learning & $\begin{array}{c}\text { Open and distance learning } \\
\text { (limit the numbers } \\
\text { of students) }\end{array}$ & $\begin{array}{l}\text { Distance learning } \\
\text { or suspended }\end{array}$ \\
\hline $\begin{array}{l}\text { Public institutions } \\
\text { and companies }\end{array}$ & $\begin{array}{l}\text { Teleworking is recommended } \\
\text { (one-third of all } \\
\text { the employees) }\end{array}$ & $\begin{array}{l}\text { Teleworking is } \\
\text { recommended (half of } \\
\text { all employees) }\end{array}$ & $\begin{array}{l}\text { Teleworking is obligated } \\
\text { except essential members }\end{array}$ \\
\hline $\begin{array}{l}\text { Private institutions } \\
\text { and companies }\end{array}$ & Flexible teleworking & $\begin{array}{l}\text { Teleworking is } \\
\text { recommended }\end{array}$ & $\begin{array}{l}\text { Teleworking is obligated } \\
\text { except essential members }\end{array}$ \\
\hline
\end{tabular}

\subsection{Air Quality Data}

The Korean Ministry of Environment (KMOE) has reported the air quality levels in about 16 administrative districts (currently 17) since 2002 and has released data to the public since 2005 
(www.airkorea.or.kr/web). In Seoul and Daegu, where the study targets are located, 25 and 15 air monitoring networks, respectively, are operated (see Figure 1) and provide daily and hourly data for $\mathrm{PM}_{2.5}, \mathrm{PM}_{10}, \mathrm{SO}_{2}, \mathrm{CO}, \mathrm{NO}_{2}$, and $\mathrm{O}_{3}$. Air pollution data were collected from January 2012 to July 2020 for comparison with the previous three years of each pandemic outbreak, including 2020 when COVID-19 occurred and 2015 when MERS-CoV occurred in Korea $\left(\mathrm{PM}_{2.5}\right.$ has been monitored since 2015). In addition, meteorological conditions are presented in Table S1.

The air quality index (AQI) explains air quality in a quantitative way to make it easier for the public to understand and to protect them from air pollution [23], initially implemented in 1999 by the US Environmental Protection Agency (USEPA). The individual indexes of the six criteria pollutants are calculated by Equation (1), and the maximum value is determined as the AQI. The AQI is divided into six color-coded categories (green-maroon), and each color is identified by a simple informative descriptor. Higher AQI values mean greater concern for people's health.

$$
\mathrm{I}_{\mathrm{p}}=\frac{\mathrm{I}_{\mathrm{Hi}}-\mathrm{I}_{\mathrm{Lo}}}{\mathrm{BP}_{\mathrm{Hi}}-\mathrm{BP}_{\mathrm{Lo}}}\left(\mathrm{C}_{\mathrm{p}}-\mathrm{BP}_{\mathrm{Lo}}\right)+\mathrm{I}_{\mathrm{Lo}}
$$

where

$\mathrm{I}_{\mathrm{p}}=$ the index for pollutant $\mathrm{p}$;

$\mathrm{C}_{\mathrm{p}}=$ the truncated concentration of pollutant $\mathrm{p}$;

$\mathrm{BP}_{\mathrm{Hi}}=$ the concentration breakpoint that is greater than or equal to $\mathrm{C}_{\mathrm{p}}$;

$\mathrm{BP}_{\mathrm{Lo}}=$ the concentration breakpoint that is less than or equal to $\mathrm{C}_{\mathrm{p}}$;

$\mathrm{I}_{\mathrm{Hi}}=$ the $\mathrm{AQI}$ value corresponding to $\mathrm{BP}_{\mathrm{Hi}}$;

$\mathrm{I}_{\mathrm{Lo}}=$ the $\mathrm{AQI}$ value corresponding to $\mathrm{BP}_{\mathrm{Lo}}$.

\subsection{Data Analysis}

Statistical analyses were performed using SPSS. A p-value of less than 0.05 was considered statistically significant. In this study, $24 \mathrm{~h}$ averages were used for $\mathrm{PM}_{2.5}, \mathrm{PM}_{10}, \mathrm{SO}_{2}, \mathrm{CO}$, and $\mathrm{NO}_{2}$, and $8 \mathrm{~h}$ averages were used for $\mathrm{O}_{3}$. The means and standard deviation (SD) were calculated to describe the level of each pollutant. The air quality and meteorological conditions in 2020 and previous years were compared using paired $t$-tests and Mann-Whitney $\mathrm{U}$ tests between the same dates.

\section{Results and Discussion}

\subsection{COVID-19 Outbreak and Social Distancing in Korea}

Figure 2 shows the trend in COVID-19 diffusion and changes in the social distancing levels in Seoul and Daegu, South Korea. In Daegu, the confirmed cases began to surge on February 18. By February 29, there were 2236 cases (71\% of the confirmed Korean cases); on March 31, there were 6684 cases (68\%); and on August 31, 2020, there were 7047 cases (35\%). The number of confirmed cases increased consistently in Seoul, but was relatively slow compared to Daegu at the early stage of the epidemic, where the spread by cluster infections increased in August. On February 29, there were 77 cases (2\%); on March 31, there were 450 cases (4\%); and on August 31, there were 3867 cases $(19 \%)$. It is noteworthy that the spread of COVID-19 in South Korea surged first in February and entered the second phase of a surging trend most recently in August.

After the first confirmed case of COVID-19 occurred on 20 January 2020, the Korean government set its infectious disease alert level to yellow. It raised its alert to red after the number of COVID-19 cases surged, especially around Daegu (February 23). As a result, since the end of February, social distancing has been in effect among the citizens. To prevent cluster infections, the social distancing level was tightened and applied until April 19. COVID-19 cases significantly reduced during active participation in social distancing measures. As the number of newly confirmed cases and unclear infection routes has decreased, the guidelines have shifted from social distancing to distancing in daily life. 


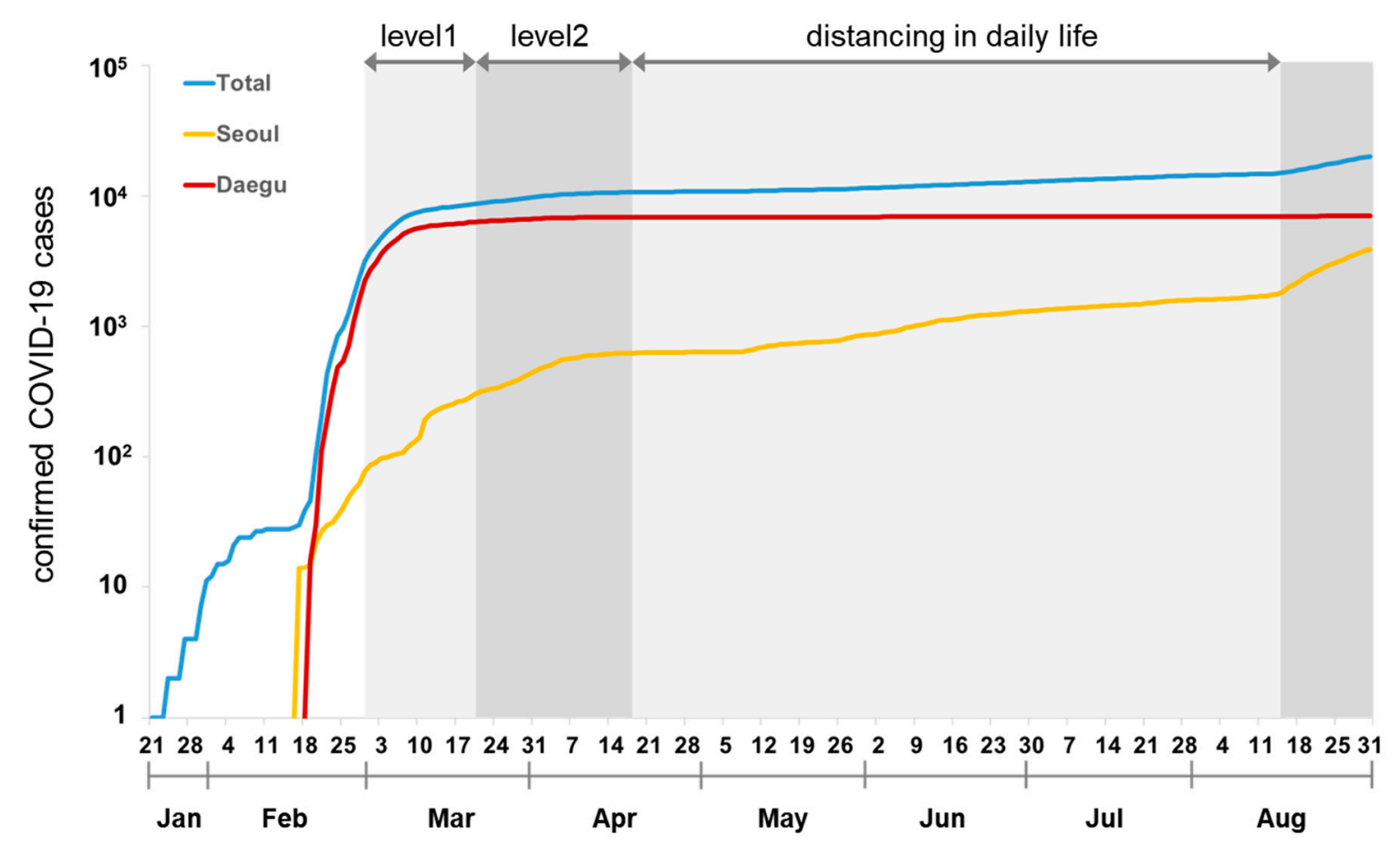

Figure 2. Daily new confirmed cases and changes in social distancing (SD) level. The blue line represents the whole country, the yellow line represents Seoul, and the red line represents Daegu.

In a field test study in a hospital, all air samples were confirmed negative at $2 \mathrm{~m}$ or more from the bed used by a patient with COVID-19 [24]. Therefore, it seems that social distancing was helpful in suppressing the spread of the virus in Korea.

However, as the number of cluster infection cases centered in Seoul increased again in August, social distancing was upgraded to level 2 on August 16 and further strengthened to level 2.5 around the metropolitan area on August 30 (Figure 2).

Meanwhile, Korea has already experienced MERS-CoV. The first confirmed MERS-CoV case occurred on 20 May 2015, resulting in a total of 186 confirmed cases and 38 deaths, with a fatality rate of $20.4 \%$ (Figure S1). While COVID-19 has accounted for most of the community-acquired infections, MERS-CoVs infections occurred mostly in hospitals (172/186). Due to the lack of confirmed cases, there was no need for social distancing, and the outbreak was officially declared to end in Korea on 24 December 2015.

\subsection{Comparison of Air Pollutants}

\subsubsection{Concentrations of $\mathrm{PM}_{2.5}$ and $\mathrm{PM}_{10}$}

Figure 3 represents the change in the concentrations of atmospheric PM in COVID-19 and MERS-CoV in the current year compared to the previous three years. Since March, when social distancing due to COVID-19 began, $\mathrm{PM}_{2.5}$ and $\mathrm{PM}_{10}$ have seen significant declines in both Seoul and Daegu compared to the previous three years (excluding June). The average concentration of $\mathrm{PM}_{10}$ in Seoul in March was significantly reduced from $60.3 \mu \mathrm{g} / \mathrm{m}^{3}$ over the previous three years to $45.0 \mu \mathrm{g} / \mathrm{m} 3$ in 2020 (Figure 3a). In Daegu, it was significantly reduced from $48.3 \mu \mathrm{g} / \mathrm{m}^{3}$ to $38.4 \mu \mathrm{g} / \mathrm{m}_{3}$ (Figure 3b), showing $25.4 \%$ and $21.4 \%$ rate reductions in Seoul and Daegu, respectively.

Compared to the past three years, the mean $\mathrm{PM}_{2.5}$ concentrations in March 2020 decreased by $14.2 \mu \mathrm{g} / \mathrm{m}^{3}$ and $8.49 \mu \mathrm{g} / \mathrm{m}^{3}$ in Seoul and Daegu (Figure $3 \mathrm{c}, \mathrm{d}$ ), respectively. In both cities, the reduction rates were $36 \%$ and $31 \%$, respectively, more dramatic than the decrease in $\mathrm{PM}_{10}$. In the springtime (February 29 to April 19) when yellow dust is severe, the $\mathrm{PM}_{10}$ and $\mathrm{PM}_{2.5}$ concentrations in 2020 during the social distancing period did not exceed the daily National Ambient Air Quality Standard (NAAQS) 
$\left(\mathrm{PM}_{10}, 100 \mu \mathrm{g} / \mathrm{m}^{3} ; \mathrm{PM}_{2.5}, 35 \mu \mathrm{g} / \mathrm{m}^{3}\right)$, compared to 8 and 38 times when the $\mathrm{PM}_{10}$ and $\mathrm{PM}_{2.5}$ standards, respectively, were exceeded in the past three years [20].

COVID-19 (2020 vs 2017-2019)
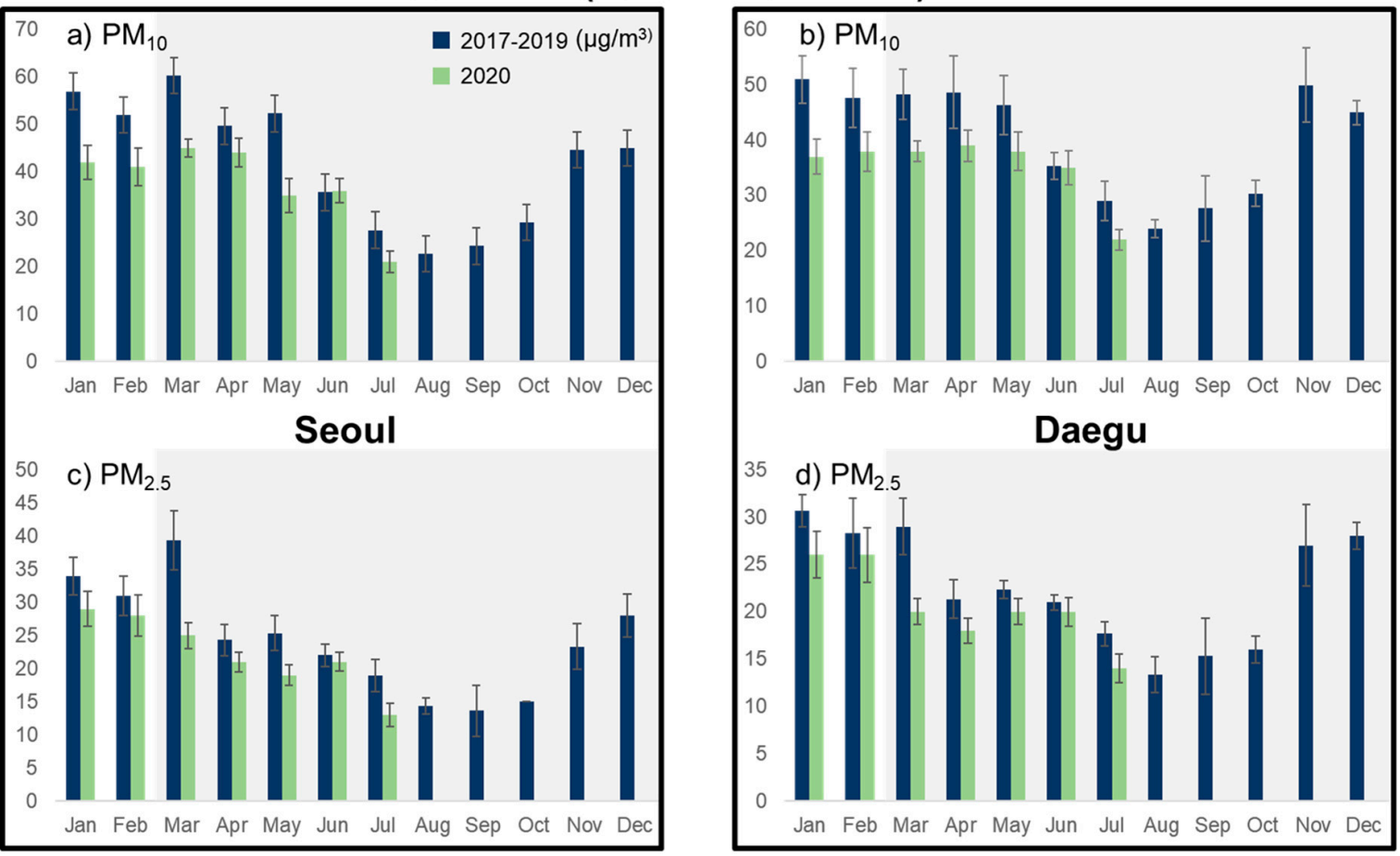

MERS-CoV (2015 vs 2012-2014)
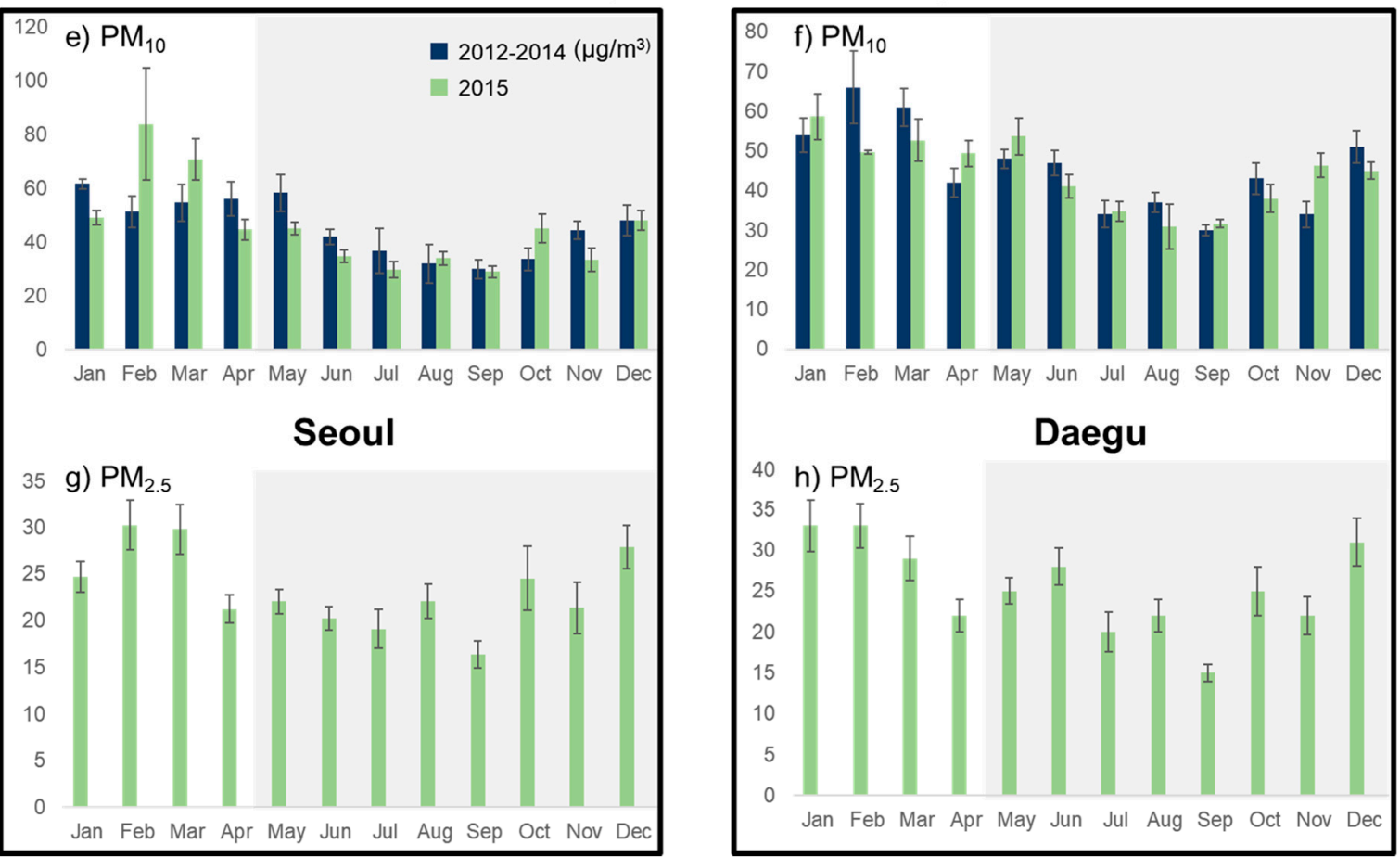

Figure 3. Comparison of $\mathrm{PM}_{2.5}\left(\mu \mathrm{g} / \mathrm{m}^{3}\right)$ and $\mathrm{PM}_{10}\left(\mu \mathrm{g} / \mathrm{m}^{3}\right)$ before and after coronavirus outbreak. $(\mathbf{a}, \mathbf{c})$ Changes in concentrations of particulate matter before and after COVID-19 in Seoul. $(\mathbf{b}, \mathbf{d})$ Changes in concentrations of particulate matter before and after COVID-19 in Daegu. $(\mathbf{e}, \mathbf{g})$ Changes in particulate matter before and after MERS-CoV in Seoul. (f,h) Changes in particulate matter before and after MERS-CoV in Daegu. ( $\mathrm{PM}_{2.5}$ has been monitored since 2015.) 
In contrast, the comparison of the PM concentrations before and after the occurrence of MERS-CoV showed no significant results, although the concentrations slightly decreased in Seoul (Figure 3e). Since the end of May, right after the outbreak of MERS-CoV, there has been a campaign to manage the personal hygiene of citizens around metropolitan areas, but there have been no social distancing policies, and only one confirmed case occurred in Daegu. At that time, there were no government guidelines related to social distancing because most MERS-CoV confirmed cases occurred within hospitals, and there were no identified cluster infections. Therefore, no changes in the $\mathrm{PM}_{10}$ and $\mathrm{PM}_{2.5}$ concentrations were observed due to MERS-CoV. Moreover, there were 186 confirmed cases, significantly less than with COVID-19, with a relatively weak impact than COVID-19 pandemic.

Interestingly, South Korea had already experienced a decline in $\mathrm{PM}_{10}$ and $\mathrm{PM}_{2.5}$ since January, before social distancing took place. The anthropogenic emissions from neighboring countries negatively affect the Korean Peninsula, and about $67 \%$ of the $\mathrm{PM}_{10}$ is due to transboundary particles [25]. In particular, China's impact on the PM in South Korea averages 30 to $50 \%$, with its contribution rising to $80 \%$ on the most polluted days according to a report by KMOE [26].

In Wuhan, China, where the novel coronavirus was first reported, air quality improvements including $\mathrm{PM}_{2.5}, \mathrm{PM}_{10}, \mathrm{NO}_{2}, \mathrm{SO}_{2}$, and $\mathrm{CO}$ have been reported from January 2020. In the case of $\mathrm{PM}_{2.5}$, it decreased by $36.2 \%$ and $44.0 \%$ in January and February, respectively (compared to the average concentrations of the previous three years) [6]. The reduction rate of $\mathrm{PM}_{2.5}$ was similar or slightly higher than that observed in our study, confirming that the strict COVID-19 control had a significant impact on air quality.

During the lockdown period, in eastern China, contiguous to Korea, a reduction in $\mathrm{PM}_{2.5}$ of $48 \%$ was also observed [27]. Therefore, the decrease in PM across China due to the COVID-19 lockdown has probably affected the air quality in South Korea since January and, along with a sharp decline in human activities due to social distancing practices since March, has led to a dramatic decrease in PM concentrations.

To further investigate these effects, we analyzed the $\mathrm{PM}_{2.5} / \mathrm{PM}_{10}$ ratio before and after social distancing, as shown in Figure 4. Because the emission source varies depending upon the size of $\mathrm{PM}$, the $\mathrm{PM}_{2.5} / \mathrm{PM}_{10}$ ratio can be used to identify the source [28]. A higher ratio means that $\mathrm{PM}_{2.5}$ anthropogenic activities contributed more, and a lower ratio suggests the contribution of many coarse particles from natural sources such as sand dust or wildfires [29].

The $\mathrm{PM}_{2.5} / \mathrm{PM}_{10}$ ratios decreased from 0.66 to 0.54 and from 0.68 to 0.54 in Seoul and Daegu (Figure $4 \mathrm{a}, \mathrm{b}$ ), respectively, shortly after the implementation of social distancing. Even if the $\mathrm{PM}_{2.5} / \mathrm{PM}_{10}$ ratio is affected by spatio-temporal variables, this significant reduction in the ratio can be explained by a decrease in anthropogenic emissions after social distancing. After social distancing, the average traffic volume decreased by more than $30 \%$ in the first week of March, mainly in the metropolitan area. In particular, from the end of February when the number of confirmed cases exploded in Daegu, the total traffic volume including public transportation decreased by up to $69 \%$ [30].

What is important is that changes in the $\mathrm{PM}_{2.5} / \mathrm{PM}_{10}$ ratio have been observed since around March 11, 12 days after the implementation of social distancing (February 29). These sudden changes are probably due to the influence of meteorological conditions including wind and temperature [10]. We observed that the temperature around March 11 was $2.7^{\circ} \mathrm{C}$ higher than the weekly average, and the wind speed was $0.7 \mathrm{~m} / \mathrm{s}$ stronger, accelerating the atmospheric dispersion. Similarly, the lowest levels of $\mathrm{PM}_{2.5}$ around March 20, March 28, and April 23 were analyzed because of the higher temperature and wind speed than the weekly average.

In addition, we observed that the $\mathrm{PM}_{2.5} / \mathrm{PM}_{10}$ ratio began to increase after social distancing was relaxed. Therefore, we confirmed the delayed effects of human activity on the distribution of particulate matter during the period when the atmosphere was stagnant [31]. 


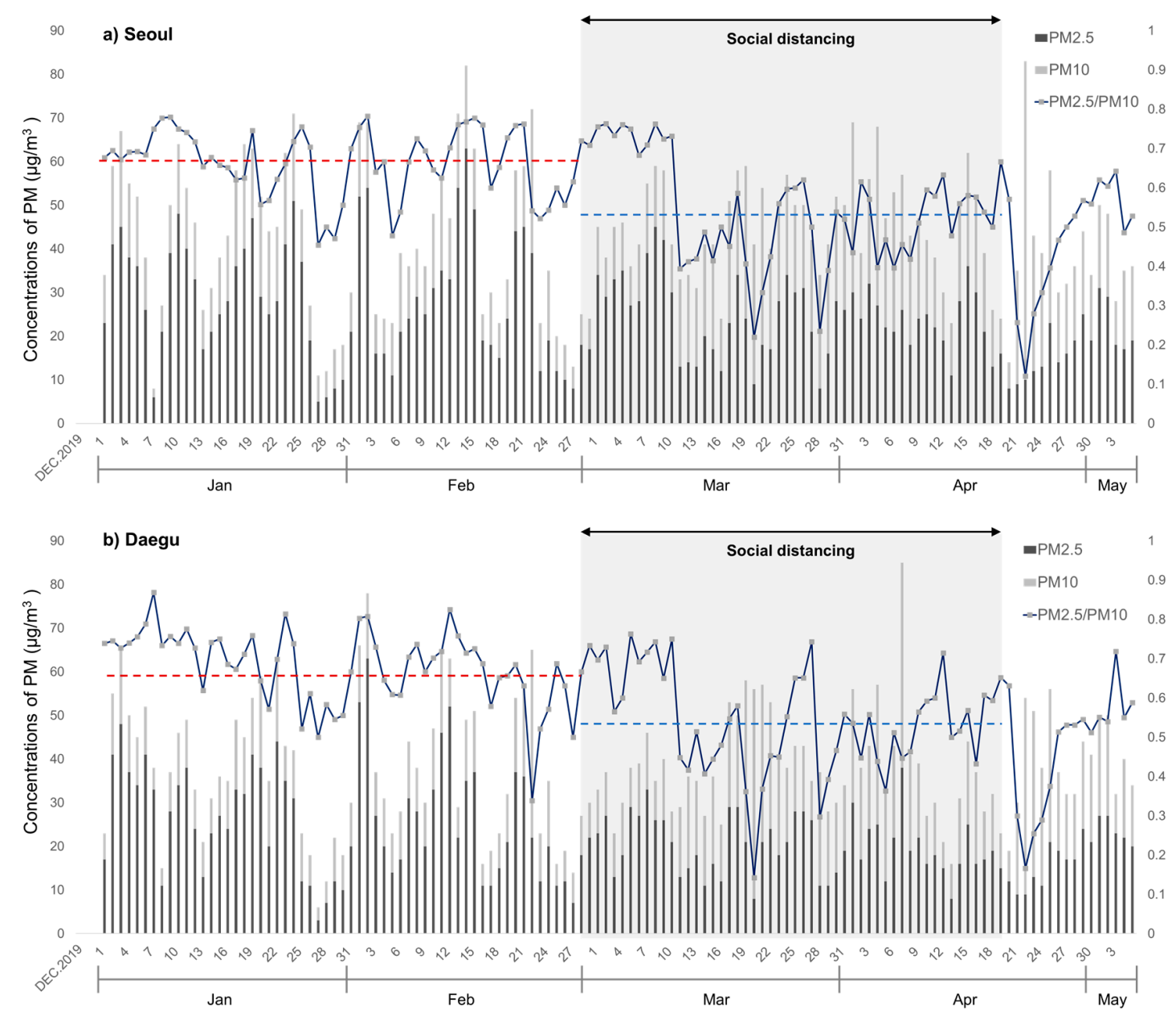

Figure 4. Changes of $\mathrm{PM}_{2.5} / \mathrm{PM}_{10}$ ratio after social distancing (a: Seoul, b: Daegu). Highlighted shadow represents the period of social distancing.

\subsubsection{Concentrations of Gaseous Pollutants}

Changes in $\mathrm{SO}_{2}$ and $\mathrm{CO}$ concentrations before and after the coronavirus outbreak are shown in Figure 5. A significant decrease in the concentration of $\mathrm{SO}_{2}$ since COVID-19 was observed for all periods in Seoul (March to July), with slight differences in Daegu (Figure 5a,b). However, Seoul does not have significant emission sources such as from industrial activities $[19,20]$, so there is little evidence that the change in $\mathrm{SO}_{2}$ concentration was caused by social distancing. South Korea strictly regulates $\mathrm{SO}_{2}$ emissions under the Chemicals Control Act, which has led to a continuous slight decrease in the concentration every year (Figure S2).

Previous studies observed a dramatic decrease in $\mathrm{SO}_{2}$ due to China's COVID-19 lockdown [6] and an $\mathrm{SO}_{2}$ movement from China to Korea through the Yellow Sea based on backward trajectory analysis [32]. In addition, the concentration of $\mathrm{SO}_{2}$ in Korea is affected by about $20-40 \%$ of the $\mathrm{SO}_{2}$ generated in China [27]. In Korea, social distancing, a weaker measure than lockdown, was adopted, and there were no restrictions on industrial activities significantly related to $\mathrm{SO}_{2}$ emission. For this reason, we estimated that reductions in trans-boundary $\mathrm{SO}_{2}$ and regulation of $\mathrm{SOx}$ emissions had a greater effect on the changes in $\mathrm{SO}_{2}$ than social distancing, consistent with previous findings $[19,20]$.

The concentration of $\mathrm{CO}$ was reduced in Seoul in March and April and in Daegu in March (Figure $5 c, d$ ). A previous study also showed results consistent with our study, but the observation period was short, from February to March, and there was no year-by-year analysis [19]. We believe that the short-term decline in CO level was due to the decrease in traffic-related CO emissions in Seoul and Daegu. However, this change was very short-lived, and the atmospheric CO returned 
to its annual average level due to the effect of traffic increases after mitigation by social distancing. After alleviating social distancing, the use of public transportation decreased due to concerns about COVID-19 infection, but the total traffic volume recovered to $97.5 \%$ of the average level as the use of private cars increased [33].

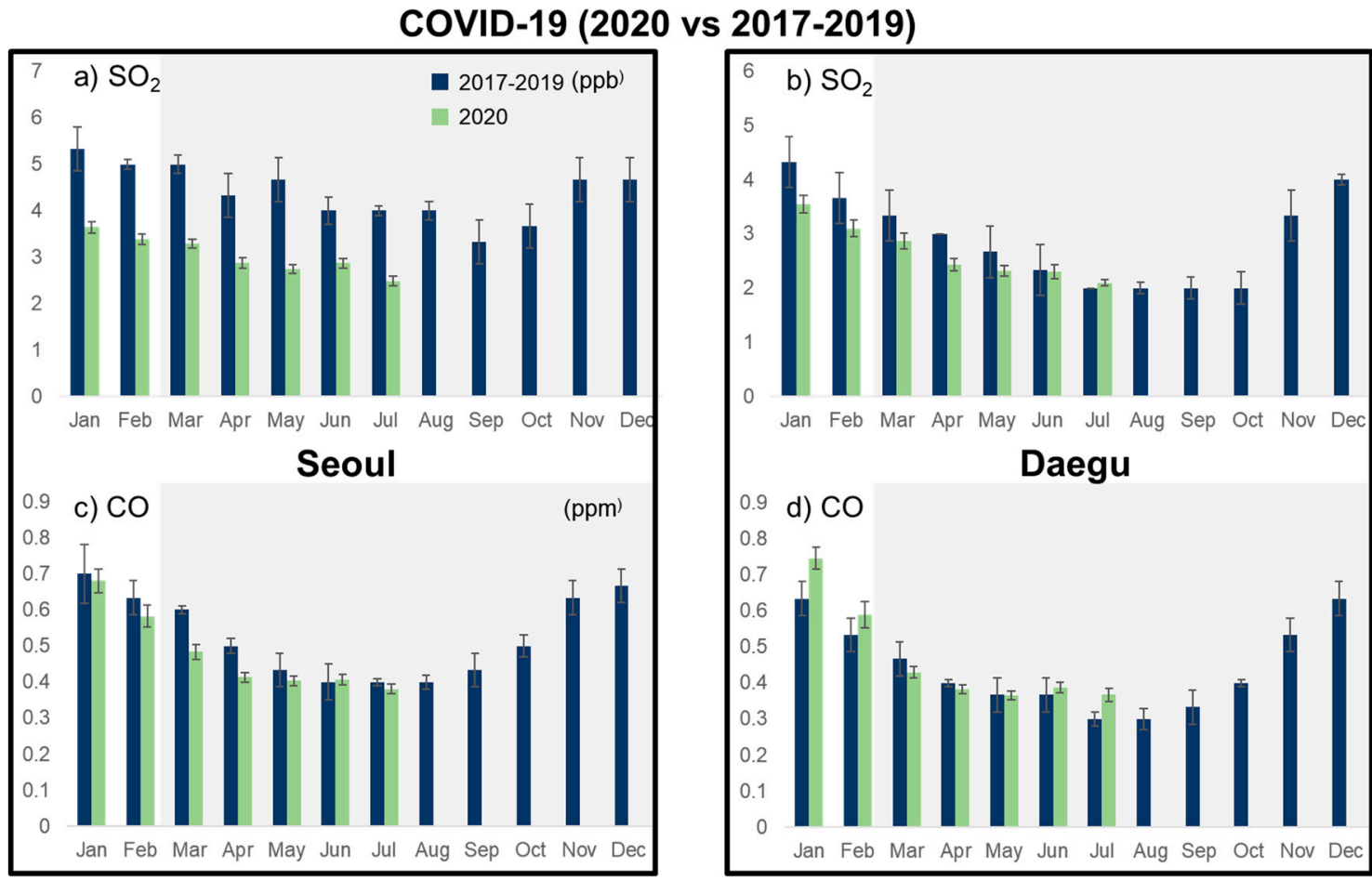

MERS-CoV (2015 vs 2012-2014)
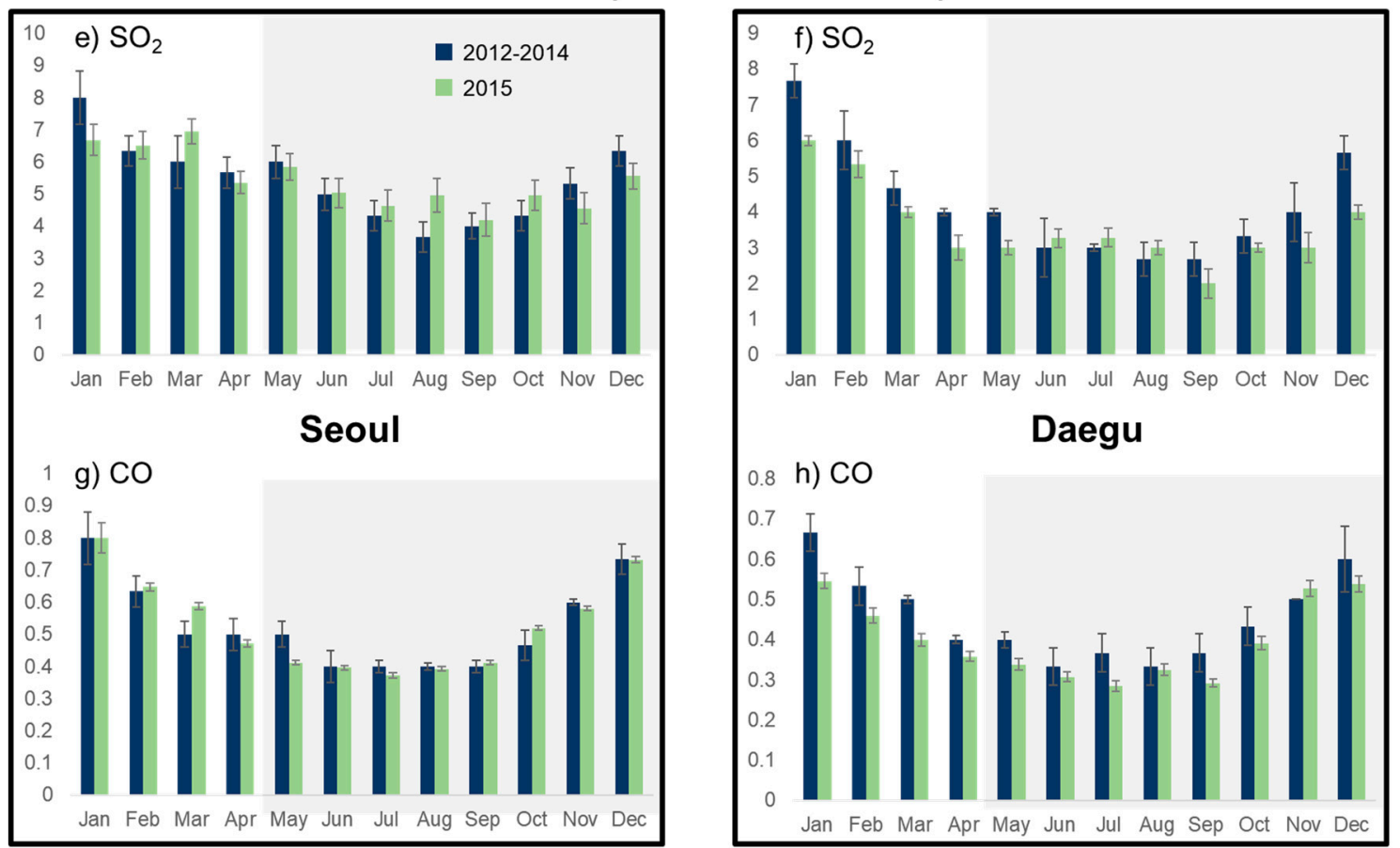

Figure 5. Comparison of $\mathrm{SO}_{2}(\mathrm{ppb})$ and $\mathrm{CO}(\mathrm{ppm})$ before and after coronavirus outbreaks. (a,c) Changes in $\mathrm{SO}_{2}$ and $\mathrm{CO}$ level before and after COVID-19 in Seoul. $(\mathbf{b}, \mathbf{d})$ Changes in $\mathrm{SO}_{2}$ and $\mathrm{CO}$ level before and after COVID-19 in Daegu. (e,g) Changes in $\mathrm{SO}_{2}$ and $\mathrm{CO}$ level before and after MERS-CoV in Seoul. $(\mathbf{f}, \mathbf{h})$ Changes in $\mathrm{SO}_{2}$ and $\mathrm{CO}$ level before and after MERS-CoV in Daegu. 
After social distancing, the year-by-year $\mathrm{NO}_{2}$ concentration decreased significantly from March to May in Seoul and Daegu (Figure 6a,b). The largest decline occurred in Seoul (April), decreased by $9.3 \mathrm{ppb}$. As described earlier, the $\mathrm{NO}_{2}$ concentrations in June and July, when social distancing was eased and traffic-related human activities were restored, were not different from the previous three years.

COVID-19 (2020 vs 2017-2019)
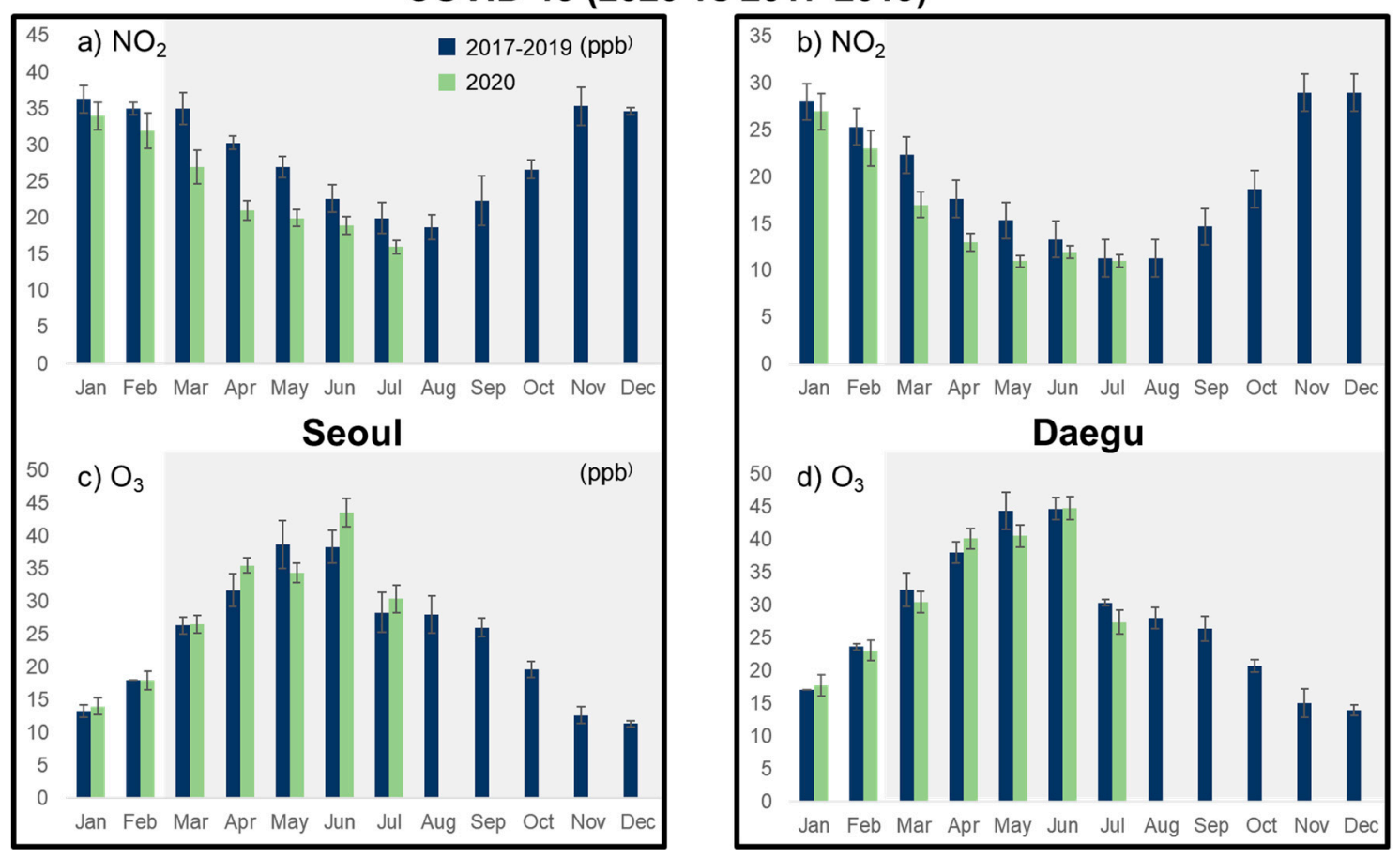

MERS-CoV (2015 vs 2012-2014)
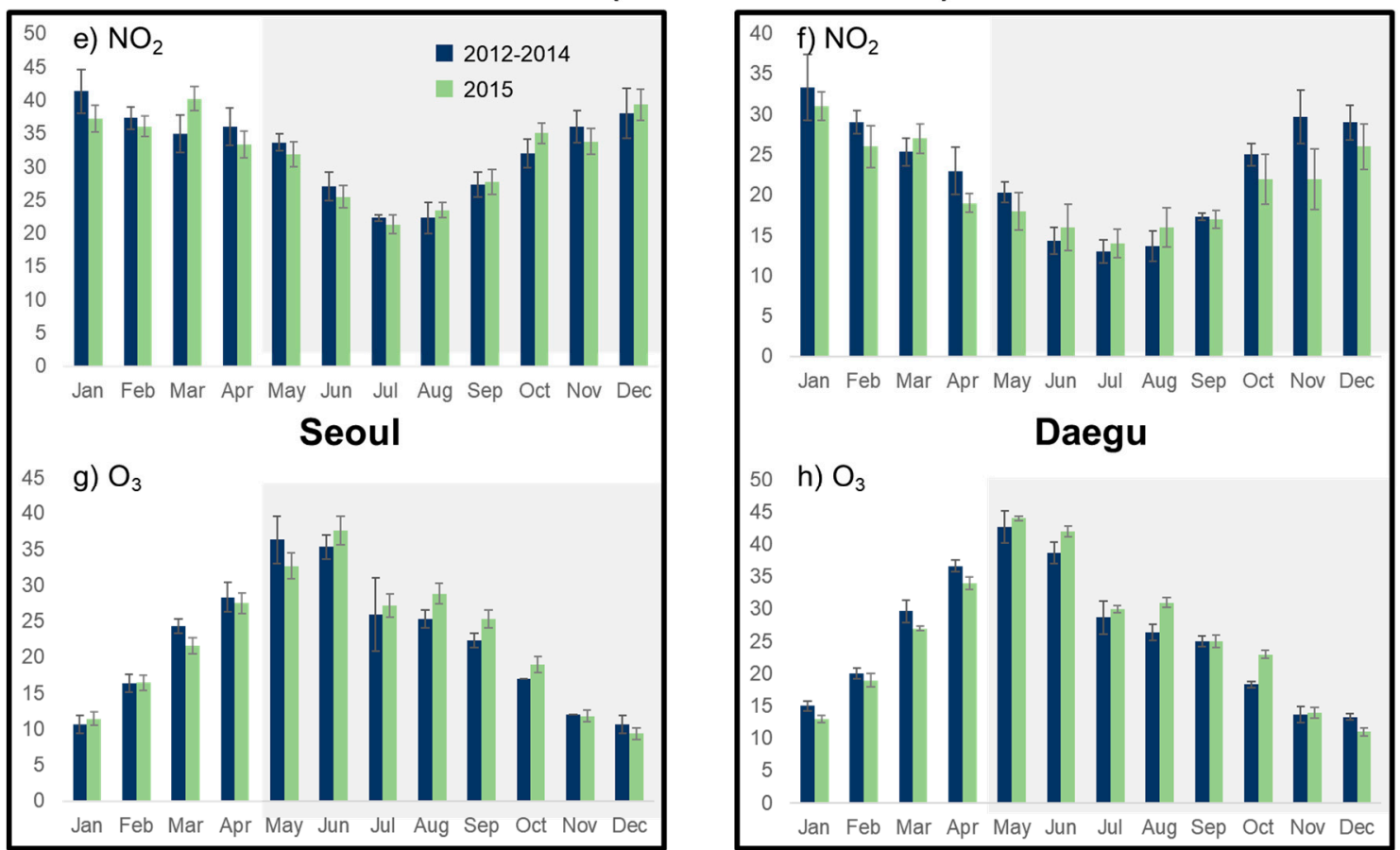

Figure 6. Comparison of $\mathrm{NO}_{2}(\mathrm{ppb})$ and $\mathrm{O}_{3}(\mathrm{ppb})$ before and after coronavirus outbreaks. (a,c) Changes in $\mathrm{NO}_{2}$ and $\mathrm{O}_{3}$ level before and after COVID-19 in Seoul. (b,d) Changes in $\mathrm{NO}_{2}$ and $\mathrm{O}_{3}$ level before and after COVID-19 in Daegu. (e,g) Changes in $\mathrm{NO}_{2}$ and $\mathrm{O}_{3}$ level before and after MERS-CoV in Seoul. $(\mathbf{f}, \mathbf{h})$ Changes in $\mathrm{NO}_{2}$ and $\mathrm{O}_{3}$ level before and after MERS-CoV in Daegu. 
Many scholarly works have reported significant increases in $\mathrm{O}_{3}$ levels [34-37] since worldwide restrictions such as social distancing and the COVID-lockdown were implemented. This is because lower levels of $\mathrm{NO}_{2}$ inhibit the dissociation to $\mathrm{NO}$ and $\mathrm{O}\left({ }^{3} \mathrm{P}\right)$, reducing the possibility of $\mathrm{NO}$ reacting with $\mathrm{O}_{3}$, resulting in an increase in $\mathrm{O}_{3}$ concentrations.

However, in this study, the trends of $\mathrm{NO}_{2}$ and $\mathrm{O}_{3}$ concentrations were changed reversely, but significant year-by-year changes in $\mathrm{O}_{3}$ concentrations were not observed (Figure $6 c, d$ ), consistent with a previous study in Korea [20]. In addition, the increase in $\mathrm{O}_{3}$ from spring to summer only reflects the trends in annual atmospheric changes in Korea.

Meanwhile, no significant changes in the year-by-year concentrations of gaseous pollutants were observed in the two cities (Figure $5 \mathrm{e}-\mathrm{h}$, Figure $6 \mathrm{e}-\mathrm{h}$ ) because there was no marked change in human activity, including the operation of industrial facilities or traffic volume, since the MERS-CoV outbreak.

We observed a significant improvement in particulate matter and a partial reduction in gaseous pollutants after social distancing. However, changes in the air quality of neighboring countries had an effect on Korea even before social distancing, and this effect needs to be detailed through further studies from a long-term perspective.

\subsection{Changes in Air Quality from Social Distancing}

The average monthly AQI in 2020 and over the three previous years was analyzed to assess the impact of COVID-19 events on changes in air quality (Figure 7). In general, South Korea experiences a severe deterioration in air quality due to the influence of Asian dust in spring [38,39]. However, from March to May the AQI fell considerably in 2020 in contrast to the higher level in the two cities over the past three years. The largest decline in the AQI occurred in April and May due to a dramatic decrease in $\mathrm{PM}_{2.5}$ immediately after social distancing. The decline was further observed in the trend in monthly changes in the AQI, which was similar to that of previous years. However, after May 5, relaxed social distancing probably weakened the effect on improving the air quality due to increased human activities. However, the AQI remained lower than the average AQI of the past three years.

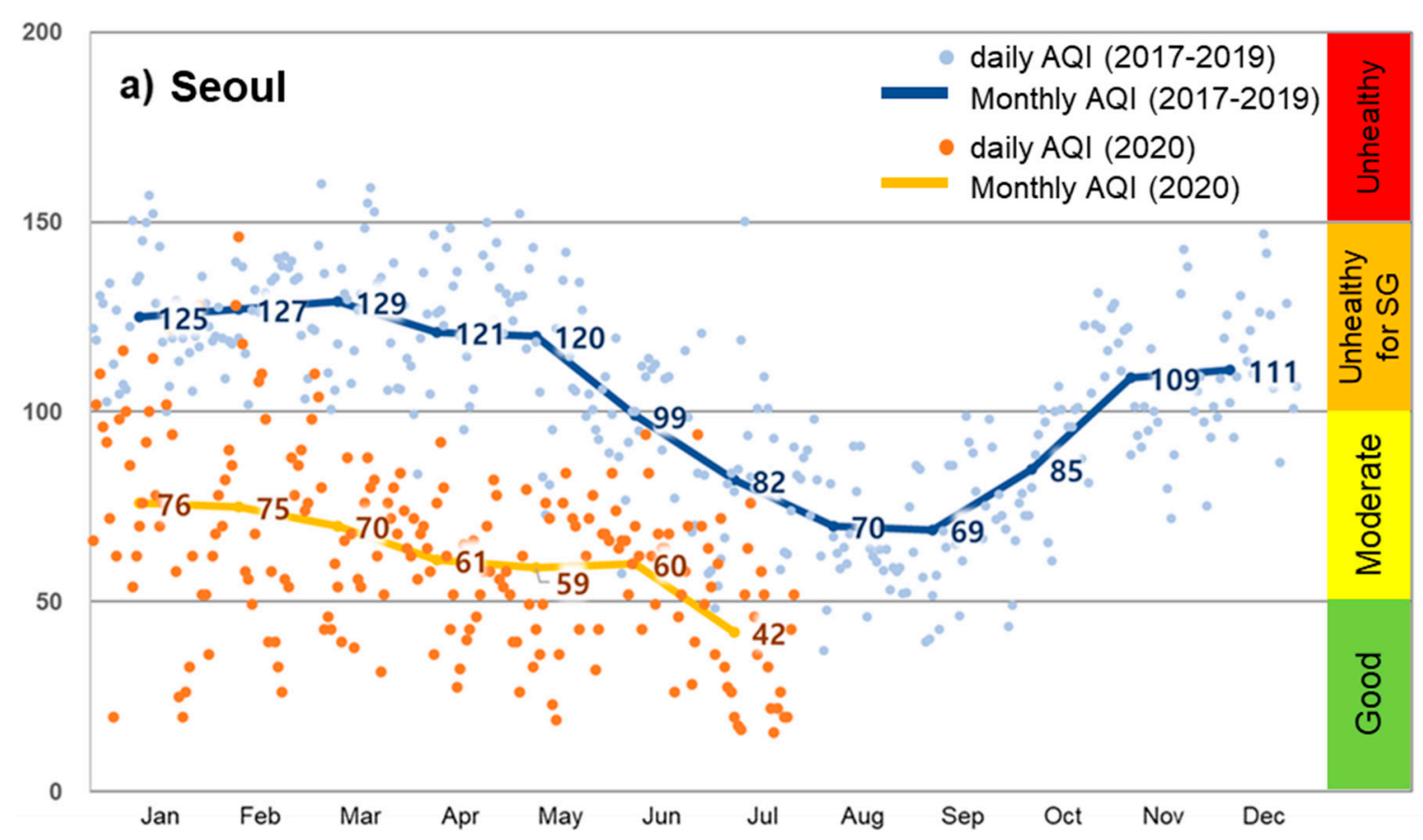

Figure 7. Cont. 


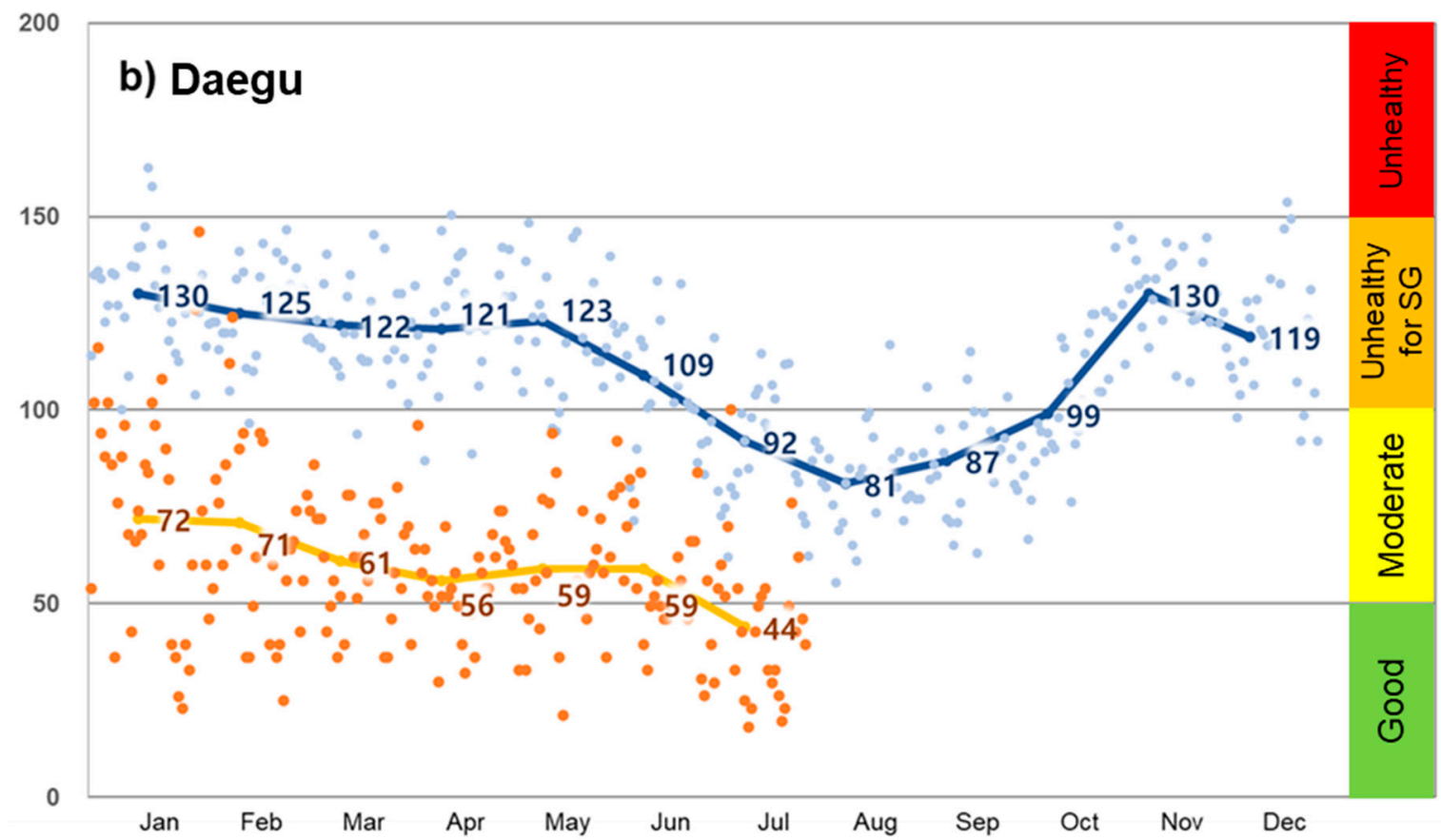

Figure 7. Comparison of daily and monthly air quality index (AQI) between 2020 and the previous three years ((a) Seoul, (b) Daegu). Categories of the AQI are "good" (green, 0-50), "moderate" (yellow, 51-100), "unhealthy for sensitive groups (SG)" (orange, 101-150), and "unhealthy" (red, 151-200). "Very unhealthy" (purple, 201-300) and "hazardous" (maroon, 301-500) were not observed in this study.

We identified the major pollutants affecting the AQI. The distributions of the indicatory pollutants according to each AQI class before and after social distancing are shown in Tables S2 and S3. The reduction of the AQI score in April was remarkable, and the AQI improvements of $44.8 \%$ and $48.7 \%$, respectively, in Seoul and Daegu was notable compared to 2017-2019. Interestingly, $\mathrm{SO}_{2}$ and CO were never responsible for the AQI score. In both cities, $\mathrm{PM}_{2.5}$ was responsible for more than $90 \%$ of AQI score. Compared to February, the air quality in March improved considerably and never exceeded 100 (unhealthy for sensitive groups) in Daegu. The March AQI score in Seoul also exceeded 100 by only $6.5 \%$, which was significantly lower than in January $(19.4 \%)$ and February $(22.6 \%)$. Since March, $\mathrm{PM}_{10}$ has been identified as the primary pollutant affecting the AQI, but it is negligible, and the contribution of $\mathrm{O}_{3}$ was seen in July due to the increased temperature and facilitation of reactions producing $\mathrm{O}_{3}$. However, the AQI derived from $\mathrm{O}_{3}$ was equivalent to Class 1 (good). Similarly, in the previous year, $\mathrm{PM}_{2.5}$ was responsible for more than $90 \%$ of the AQI score, followed by $\mathrm{O} 3$ and $\mathrm{PM}_{10}$.

Although decreases in the $\mathrm{PM}_{2.5} / \mathrm{PM}_{10}$ ratio after social distancing supported the decrease in contributions from anthropogenic emissions, the AQI analysis results confirmed that $\mathrm{PM}_{2.5}$ was still a key contributor to air quality in South Korea.

\section{Conclusions}

To assess the effects of social distancing on air quality due to COVID-19 in Seoul and Daegu, six representative air pollutants were analyzed and the AQI distribution was observed. The comparison between 2020 and the previous three years revealed a significant drop in PM compared to gaseous pollutants. In both cities, the mean March $\mathrm{PM}_{2.5}$ concentration showed a dramatic decline of $31-36 \%$. After social distancing, the $\mathrm{PM}_{2.5} / \mathrm{PM}_{10}$ ratio was reduced by about $19 \%$ from 0.68 to 0.54 , confirming that traffic-related $\mathrm{PM}_{2.5}$ emissions were decreased due to reductions in human activities. A partial decrease in $\mathrm{CO}$ and $\mathrm{NO}_{2}$ was observed, which, as with $\mathrm{PM}_{2.5}$, was related to the reduction in vehicle emissions. It was not clear whether the reduction in $\mathrm{SO}_{2}$ concentrations was the result of social distancing. However, reductions in the transboundary $\mathrm{SO}_{2}$ proved that COVID-19 control actions 
could affect the air quality across borders as well within a country. The change in $\mathrm{O}_{3}$ due to COVID-19 did not produce results consistent with prior studies and suggests that further research is needed to reflect meteorological conditions.

During the observation period, $\mathrm{PM}_{2.5}$ was responsible for more than $90 \%$ of the AQI score regardless of the COVID-19 pandemic occurrence. In Korea, the indicatory pollutant is $\mathrm{PM}_{2.5}$, and we suggest that the rapid decline in traffic volume (30-69\%) in the early social distancing period led to significant air quality improvement, as in the case of megacities around the world experiencing COVID-19.

Notably, after the implementation of 'distancing in daily life', a weakened social distancing, traffic volume recovered to $97.5 \%$ compared to pre-COVID-19, similar to the pattern of changes in air pollutants. Our findings support that air pollution is directly related to traffic.

Korea has experienced an improvement in air quality due to the reduction in transboundary pollutants from neighboring countries since COVID-19 first occurred, and it has experienced a significant decrease in the AQI in conjunction with the effect of social distancing. In particular, the improvement in air quality in April is an exceptional example of COVID-19 control action having a positive effect on air quality. Significant changes in air quality were observed in countries adopting strict COVID lockdown policies. Even in Korea, which adopted weaker guidelines of social distancing, the overall air quality was significantly improved. If the chemical composition analysis of $\mathrm{PM}_{2.5}$ was added, the impact of neighboring countries and domestic sources could be analyzed in more detail.

Despite the significant air quality improvement found in Seoul and Daegu, there are some differences in the spread of COVID-19. In Daegu, the number of confirmed cases exploded in the early stages of the COVID-19 outbreak, while Seoul showed a steady increase. Meanwhile, the outbreak in Seoul in August led to the second pandemic of COVID-19 in Korea. Therefore, we suggest that further studies are needed to approach air quality according to the extent of COVID-19.

Our findings indicate that the national decisions to limit human activities led to changes in regional and temporal air pollution levels and support the need for cross-border cooperation to improve air quality in the East Asia region. The on-going COVID-19 pandemic has caused global economic stagnation, increased disease burden, and even mental health effects, but some positive effects on the global environment, including improvements in air quality, suggest a direction for a sustainable environment in the post-COVID-19 era.

Supplementary Materials: The following are available online at http://www.mdpi.com/2073-4433/11/10/1137/s1, Table S1. Comparison of meteorological conditions (the same dates in 2020 and the previous 3 years), Table S2. Distribution of contributary pollutants of monthly AQI in Seoul, Table S3. Distribution of contributary pollutants of monthly AQI in Daegu. Figure S1, the number of daily confirmed cases and deaths for MERS-CoV in Korea (2015), Figure S2. The annual estimated emissions of SOx in Korea.

Author Contributions: Conceptualization, J.H.S. and J.-R.S.; methodology, J.H.S.; validation, J.H.S. and H.W.J.; formal analysis, J.H.S. and U.J.S.; investigation, J.H.S. and U.J.S.; data curation, J.H.S and H.W.J.; writing-original draft preparation, J.H.S. and H.W.J.; writing-review and editing, J.H.S. and J.-R.S. All authors have read and agreed to the published version of the manuscript.

Funding: This research received no external funding.

Acknowledgments: The authors thank the Korea Environment Corporation for providing the air quality data.

Conflicts of Interest: The authors declare no conflict of interest.

\section{References}

1. Cucinotta, D.; Vanelli, M. WHO declares COVID-19 a pandemic. Acta Bio Med. Atenei Parm. 2020, 91, $157-160$.

2. Nakada, L.Y.K.; Urban, R.C. COVID-19 pandemic: Impacts on the air quality during the partial lockdown in São Paulo state, Brazil. Sci. Total Environ. 2020, 730, 139087. [CrossRef] [PubMed]

3. Sharma, S.; Zhang, M.; Gao, J.; Zhang, H.; Kota, S.H. Effect of restricted emissions during COVID-19 on air quality in India. Sci. Total Environ. 2020, 728, 138878. [CrossRef]

4. Huang, X.; Ding, A.; Gao, J.; Zheng, B.; Zhou, D.; Qi, X.; Tang, R.; Wang, J.; Ren, C.; Nie, W.; et al. Enhanced secondary pollution offset reduction of primary emissions during COVID-19 lockdown in China. Natl. Sci. Rev. 2020. [CrossRef] 
5. Wang, P.; Chen, K.; Zhu, S.; Wang, P.; Zhang, H. Severe air pollution events not avoided by reduced anthropogenic activities during COVID-19 outbreak. Resour. Conserv. Recycl. 2020, 158, 104814. [CrossRef] [PubMed]

6. Xu, K.; Cui, K.; Young, L.-H.; Wang, Y.-F.; Hsieh, Y.-K.; Wan, S.; Zhang, J. Air Quality Index, Indicatory Air Pollutants and Impact of COVID-19 Event on the Air Quality near Central China. Aerosol Air Qual. Res. 2020, 20, 1204-1221. [CrossRef]

7. Berman, J.D.; Ebisu, K. Changes in US air pollution during the COVID-19 pandemic. Sci. Total Environ. 2020, 739, 139864. [CrossRef] [PubMed]

8. Zangari, S.; Hill, D.T.; Charette, A.T.; Mirowsky, J.E. Air quality changes in New York City during the COVID-19 pandemic. Sci. Total Environ. 2020, 742, 140496. [CrossRef]

9. Lovarelli, D.; Conti, C.; Finzi, A.; Bacenetti, J.; Guarino, M. Describing the trend of ammonia, particulate matter and nitrogen oxides: The role of livestock activities in Northern Italy during Covid-19 quarantine. Environ. Res. 2020, 191, 110048. [CrossRef]

10. Collivignarelli, M.C.; Abbà, A.; Bertanza, G.; Pedrazzani, R.; Ricciardi, P.; Miino, M.C. Lockdown for CoViD-2019 in Milan: What are the effects on air quality? Sci. Total Environ. 2020, 732, 139280. [CrossRef]

11. Kumari, P.; Toshniwal, D. Impact of lockdown measures during COVID-19 on air quality-A case study of India. Int. J. Environ. Health Res. 2020, 1-8. [CrossRef]

12. Singh, R.P.; Chauhan, A. Impact of lockdown on air quality in India during COVID-19 pandemic. Air Qual. Atmos. Health 2020, 13, 921-928. [CrossRef] [PubMed]

13. Dantas, G.; Siciliano, B.; França, B.B.; da Silva, C.M.; Arbilla, G. The impact of COVID-19 partial lockdown on the air quality of the city of Rio de Janeiro, Brazil. Sci. Total Environ. 2020, 729, 139085. [CrossRef] [PubMed]

14. Debone, D.; da Costa, M.V.; Miraglia, S.G. 90 days of COVID-19 social distancing and its impacts on air quality and health in Sao Paulo, Brazil. Sustainability 2020, 12, 7440. [CrossRef]

15. Collaborators, G.R.F. Global, regional, and national comparative risk assessment of 84 behavioural, environmental and occupational, and metabolic risks or clusters of risks for 195 countries and territories, 1990-2017: A systematic analysis for the Global Burden of Disease Study 2017. Lancet (England) 2018, 392, 1923.

16. Ferro, A.R.; Kopperud, R.J.; Hildemann, L.M. Source strengths for indoor human activities that resuspend particulate matter. Environ. Sci. Technol. 2004, 38, 1759-1764. [CrossRef] [PubMed]

17. Goolsbee, A.; Syverson, C. Fear, lockdown, and Diversion: Comparing Drivers of Pandemic Economic Decline 2020; National Bureau of Economic Research: Cambridge, MA, USA, 2020.

18. Kroll, J.H.; Heald, C.L.; Cappa, C.D.; Farmer, D.K.; Fry, J.L.; Murphy, J.G.; Steiner, A.L. The complex chemical effects of COVID-19 shutdowns on air quality. Nat. Chem. 2020, 12, 777-779. [CrossRef]

19. Han, B.-S.; Park, K.; Kwak, K.-H.; Park, S.-B.; Jin, H.-G.; Moon, S.; Kim, J.-W.; Baik, J.-J. Air Quality Change in Seoul, South Korea under COVID-19 Social Distancing: Focusing on $\mathrm{PM}_{2.5}$. Int. J. Environ. Res. Public Health 2020, 17, 6208. [CrossRef]

20. Ju, M.J.; Oh, J.; Choi, Y.-H. Changes in air pollution levels after COVID-19 outbreak in Korea. Sci. Total Environ. 2020, 750, 141521. [CrossRef]

21. Choi, J.H.-J. The city is connections: Seoul as an urban network. Multimed. Syst. 2010, 16, 75-84. [CrossRef]

22. The Ministry of Health and Welfare of South Korea (MOHW). COVID-19. Available online: http://ncov. mohw.go.kr/bdBoardList_Real.do (accessed on 22 August 2020).

23. Bishoi, B.; Prakash, A.; Jain, V. A comparative study of air quality index based on factor analysis and US-EPA methods for an urban environment. Aerosol Air Qual. Res. 2009, 9, 1-17. [CrossRef]

24. Faridi, S.; Niazi, S.; Sadeghi, K.; Naddafi, K.; Yavarian, J.; Shamsipour, M.; Jandaghi, N.Z.S.; Sadeghniiat, K.; Nabizadeh, R.; Yunesian, M. A field indoor air measurement of SARS-CoV-2 in the patient rooms of the largest hospital in Iran. Sci. Total Environ. 2020, 725, 138401. [CrossRef] [PubMed]

25. Lee, H.-J.; Jo, H.-Y.; Kim, S.-W.; Park, M.-S.; Kim, C.-H. Impacts of atmospheric vertical structures on transboundary aerosol transport from China to South Korea. Sci. Rep. 2019, 9, 1-9. [CrossRef]

26. Joint Research Project for Long-Range Transboundary Air Pollutans in Northeast Asia (LTP); Korean Ministry of Environment (KMOE): Sejong, Korea, 2019.

27. Marlier, M.E.; Xing, J.; Zhu, Y.; Wang, S. Impacts of COVID-19 response actions on air quality in China. Environ. Res. Commun. 2020, 2, 075003. [CrossRef]

28. Xu, G.; Jiao, L.; Zhang, B.; Zhao, S.; Yuan, M.; Gu, Y.; Liu, J.; Tang, X. Spatial and temporal variability of the PM2. 5/PM10 ratio in Wuhan, Central China. Aerosol Air Qual. Res. 2016, 17, 741-751. [CrossRef] 
29. Zhao, D.; Chen, H.; Yu, E.; Luo, T. $\mathrm{PM}_{2.5} / \mathrm{PM}_{10}$ Ratios in Eight Economic Regions and Their Relationship with Meteorology in China. Adv. Meteorol. 2019, 2019, 5295726. [CrossRef]

30. The Korea Transport Institute (KOTI). Impact Analysis and Response of COVID-19 on Transportation Sector. Available online: https://www.koti.re.kr/main/covid19 (accessed on 22 August 2020).

31. Seasonal Particulate Matter (PM) Management; Korean Ministry of Environment (KMOE): Sejong, Korea, 2020.

32. Bhardwaj, P.; Ki, S.J.; Kim, Y.H.; Woo, J.H.; Song, C.K.; Park, S.Y.; Song, C.H. Recent changes of trans-boundary air pollution over the Yellow Sea: Implications for future air quality in South Korea. Environ. Pollut. 2019, 247, 401-409. [CrossRef]

33. Transport Operation \& Information Service (TOPIS). Traffic Status. Available online: https://topis.seoul.go.kr (accessed on 22 August 2020).

34. Zhang, J.; Cui, K.; Wang, Y.-F.; Wu, J.-L.; Huang, W.-S.; Wan, S.; Xu, K. Temporal variations in the air quality index and the impact of the COVID-19 event on air quality in western China. Aerosol Air Qual. Res. 2020, 20, 1552-1568. [CrossRef]

35. Hashim, B.M.; Al-Naseri, S.K.; Al-Maliki, A.; Al-Ansari, N. Impact of COVID-19 lockdown on NO2, O3, PM2. 5 and PM10 concentrations and assessing air quality changes in Baghdad, Iraq. Sci. Total Environ. 2020, 754, 141978. [CrossRef]

36. Zoran, M.A.; Savastru, R.S.; Savastru, D.M.; Tautan, M.N. Assessing the relationship between ground levels of ozone $\left(\mathrm{O}_{3}\right)$ and nitrogen dioxide $\left(\mathrm{NO}_{2}\right)$ with coronavirus (COVID-19) in Milan, Italy. Sci. Total Environ. 2020, 740, 140005. [CrossRef]

37. Zambrano-Monserrate, M.A.; Ruano, M.A. Has air quality improved in Ecuador during the COVID-19 pandemic? A parametric analysis. Air Qual. Atmos. Health 2020, 13, 929-938. [CrossRef] [PubMed]

38. Nakao, M.; Ishihara, Y.; Kim, C.-H.; Hyun, I.-G. The impact of air pollution, including Asian sand dust, on respiratory symptoms and health-related quality of life in outpatients with chronic respiratory disease in Korea: A panel study. J. Prev. Med. Public Health 2018, 51, 130. [CrossRef] [PubMed]

39. Sharma, A.P.; Kim, K.H.; Ahn, J.W.; Shon, Z.H.; Sohn, J.R.; Lee, J.H.; Ma, C.J.; Brown, R.J. Ambient particulate matter (PM10) concentrations in major urban areas of Korea during 1996-2010. Atmos. Pollut. Res. 2014, 5, 161-169. [CrossRef]

Publisher's Note: MDPI stays neutral with regard to jurisdictional claims in published maps and institutional affiliations.

(C) 2020 by the authors. Licensee MDPI, Basel, Switzerland. This article is an open access article distributed under the terms and conditions of the Creative Commons Attribution (CC BY) license (http://creativecommons.org/licenses/by/4.0/). 